\title{
Curativo com capacete para prevenção de edema e coleção subgaleal pós-operatórios
}

\author{
Antonio Carlos Montanaro, Jefferson Rosi Júnior, João de Deus da Costa Alves Júnior \\ Grupo de Apoio de Neurologia e Neurocirurgia da R. B. Sociedade Portuguesa de Beneficência de São Paulo. \\ Hospital São Joaquim. Serviço do Dr. Roberto Godoy
}

\section{RESUMO}

Num estudo prospectivo, os autores relatam os resultados em 40 pacientes submetidos a craniotomia e divididos em dois grupos: em 20 pacientes foi feito curativo simples na ferida cirúrgica e em outros 20, um curativo complexo com 4 faixas-crepe envolvendo o crânio, as orelhas e passando sob a mandíbula.

No primeiro grupo, $70 \%$ dos pacientes tiveram acúmulo de coleção subgaleal ou edema, enquanto no segundo grupo somente $5 \%$ apresentaram o mesmo problema.

Entre os fatores isolados que provocaram acúmulo de líquido no espaço subgaleal ou edema, o tempo cirúrgico foi o mais evidente.

\section{PALAVRAS-CHAVE}

Curativo. Craniotomia. Complicações pós-operatórias.

\section{ABSTRACT}

Compressive skull dressing to prevent postoperative subgaleal edema and fluid collection In a prospective study, the authors report the results of 40 patients undergone to craniotomy and divided into two groups: in 20 patients it was made a simple bandage dressing over the surgical wound and in 20 patients a complete dressing, made with four mourning bands over all the cranium, ears and passing under the mandible.

In the first group, $70 \%$ of patients had some amount of subgaleal liquid collection or edema while in the second group only $5 \%$ presented that postoperative complication.

Among the isolated factors that produced subgaleal fluid accumulation or edema, surgical duration was the most evident.

\section{KEYWORDS}

Craniotomy dressings. Craniotomy. Postoperative complications.

\section{Introdução}

Ao longo das últimas décadas, foram grandes os avanços das técnicas neurocirúrgicas proporcionando melhora significativa nos resultados. Porém, persistem alguns problemas que, mesmo não trazendo qualquer conseqüência grave para o paciente, são desagradáveis e merecem ser evitados.

O líquido que se coleta nas partes moles extracranianas, tanto na forma de edema quanto de coleção, é algo que incomoda muito o paciente no período pós-operatório, seja causando dor, seja dificultando a visão ou mesmo dificultando a higiene. Quase todo paciente assusta-se bastante quando um líquido serossanguinolento extravasa por algum pertuito remanescente entre os pontos de sutura da pele, sujando roupas de cama, travesseiro ou o próprio paciente, que, imediatamente, acha que há algo de errado. E, de fato, há. O edema ou coleção tem de ser encarado pelos neurocirurgiões como falha do procedimento cirúrgico, e medidas devem ser tomadas para evitá-lo, de modo a proporcionar um período pós-operatório mais tranqüilo ao paciente neurocirúrgico e a seus familiares, em geral já muito preocupados com o diagnóstico e o prognóstico.

$\mathrm{O}$ assunto é pouco discutido na literatura neurocirúrgica, a ponto de não ser encontrada qualquer referência bibliográfica. 


\section{Casuística e método}

Em estudo prospectivo, avaliamos 40 pacientes submetidos a craniotomia, no nosso serviço, entre 4 de setembro de 2000 e 12 de agosto de 2001, separando-os em dois grupos: no grupo A foi realizado curativo com capacete e, no grupo B, curativos feitos com solução anti-séptica, gaze e fita adesiva Micropore ${ }^{\circledR}$. Casos de reoperações foram excluídos da casuística.

Dos pacientes analisados, 14 (35\%) foram do sexo masculino e $26(65 \%)$ do sexo feminino, com extremos de idade que variaram de 7 a 83 anos, com maior número de casos na faixa dos 51 aos 60 anos, conforme a tabela 1 .

Quanto à distribuição racial, $80 \%$ eram brancos, $15 \%$ negros e 5\% amarelos.

Os vários tipos de incisão cirúrgica realizados estão relacionados na tabela 2 .

\begin{tabular}{|c|c|c|}
\hline \multicolumn{3}{|c|}{$\begin{array}{c}\text { Tabela } 1 \\
\text { Distribuição etária dos pacientes }\end{array}$} \\
\hline Idade (anos) & Número de casos & $\%$ \\
\hline $0-10$ & 1 & 2,5 \\
\hline $11-20$ & 3 & 7,5 \\
\hline $21-30$ & 3 & 7,5 \\
\hline $31-40$ & 6 & 15,0 \\
\hline $41-50$ & 9 & 22,5 \\
\hline $51-60$ & 11 & 27,5 \\
\hline $61-70$ & 4 & 10,0 \\
\hline $71-80$ & 1 & 2,5 \\
\hline$>80$ & 2 & 5,0 \\
\hline Total & 40 & 100 \\
\hline
\end{tabular}

\begin{tabular}{lc}
\hline \multicolumn{2}{c}{ Tabela } \\
\multicolumn{1}{c}{ Distribuição } & das \\
craniotomias & realizadas \\
\hline Incisão & Número de casos \\
\hline Pterional & 21 \\
Bicoronal & 9 \\
Frontotemporoparietal & 4 \\
Temporoparietoccipital & 2 \\
Parietal & 1 \\
Temporal & 1 \\
Occipital & 1 \\
Temporoparietal & 1 \\
Total & 40 \\
\hline
\end{tabular}

Em relação ao tempo cirúrgico, 14 cirurgias (35\%) tiveram duração inferior a 4 horas, outras 26 cirurgias (65\%) tiveram duração de 4 horas ou mais. Na tabela 3 , estão relacionados o tempo de cirurgia e o número de pacientes.

Em todos os pacientes passou-se solução antiséptica (PVPI ou clorexidina) sobre a sutura, cobrindo-a com gaze e fita adesiva.
Tabela 3

Distribuição dos pacientes em relação à duração da cirurgia

\begin{tabular}{ccc}
\hline Duração (horas) & Número de casos & $\%$ \\
\hline 1 & 1 & 2,5 \\
2 & 2 & 5,0 \\
3 & 11 & 27,5 \\
4 & 15 & 37,5 \\
5 & 3 & 7,5 \\
6 & 4 & 10,0 \\
7 & 3 & 7,5 \\
13 & 1 & 2,5 \\
Total & 40 & 100,0 \\
\hline
\end{tabular}

Após esse procedimento inicial e comum a ambos os grupos, naquele em que se realizou curativo com capacete, a técnica utilizada foi a seguinte: uma ou duas gazes foram totalmente abertas e enroladas no maior eixo, formandose um longo cilindro; na região frontal do lado da craniotomia, colocou-se a gaze, assim preparada, logo acima da sobrancelha, acompanhando o contorno da órbita e prendendo-a com fita adesiva nas suas extremidades; tal procedimento objetivava diminuir o edema palpebral, uma vez que os olhos não foram cobertos pelo curativo; a seguir, toda a região manipulada era coberta por gaze, dando-se atenção especial às orelhas, protegendo-as com volume maior de gaze, tanto em sua porção externa quanto entre o pavilhão auricular e o crânio (Figura 1); por último, duas faixas-crepe de $15 \mathrm{~cm}$ foram enroladas em torno do crânio, na forma do capacete clássico com inclusão das orelhas e duas outras foram enroladas a partir da região parietal passando sob a mandíbula, retornando à região parietal contralateral e, em seguida, circundando o crânio, para então repetir o ciclo (sob a mandíbula e circundando o crânio, alternadamente) até o fim das faixas; ao terminar o enfaixamento, uma fita adesiva foi colocada para prender a extremidade da faixa-crepe.

Em todos os pacientes, os curativos foram mantidos intactos por 48 horas. Em nenhum paciente foi deixado dreno.

Todos os pacientes tiveram fechamento cirúrgico feito da mesma maneira. O retalho ósseo foi fixado com fio de nylon 2-0. O músculo temporal e o tecido subcutâneo foram suturados com fio vicril 3-0 em pontos contínuos e a pele suturada com fio de nylon 2-0, em pontos contínuos ancorados.

\section{Resultados}

No total, edema ou coleção foi observado em 15 $(37,5 \%)$ dos 40 casos. A distribuição percentual dessa ocorrência em cada tipo de incisão encontra-se relacionada na tabela 4 . 

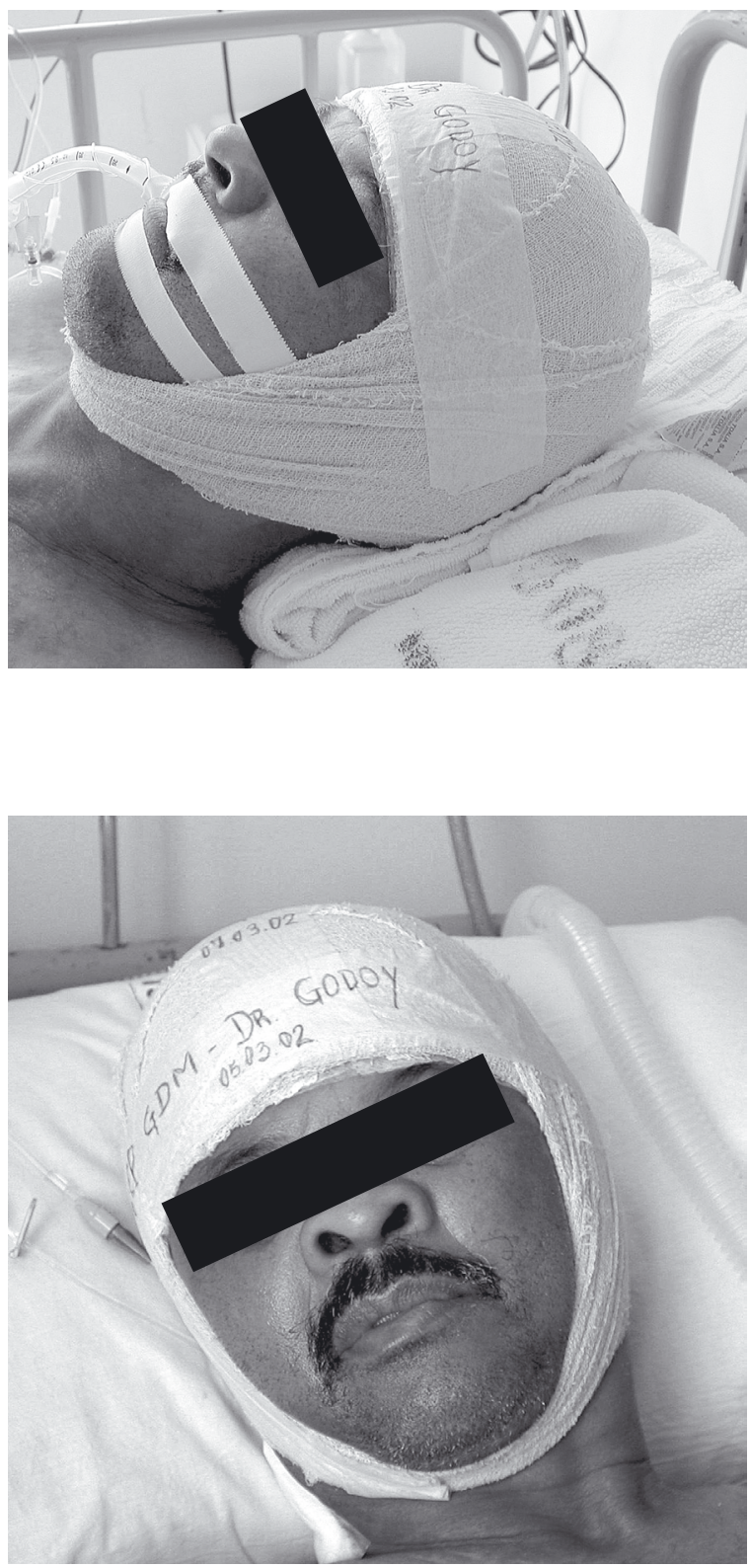

Figura 1 - Fotos mostrando paciente com o capacete descrito.

Tabela 4

Incidência de edema ou coleção nas várias craniotomias

\begin{tabular}{lcc}
\hline Incisão & Número de casos & Incidência de coleção \\
\hline Pterional & 21 & $8 / 21(38,0 \%)$ \\
Bicoronal & 9 & $1 / 9(11,1 \%)$ \\
Frontotemporoparietal & 4 & $3 / 4(75,0 \%)$ \\
Temporoparietoccipital & 2 & $0 / 2(0,0 \%)$ \\
Parietal & 1 & $0 / 1(0,0 \%)$ \\
Temporal & 1 & $1 / 1(100 \%)$ \\
Occipital & 1 & $1 / 1(100 \%)$ \\
Temporoparietal & 1 & $1 / 1(100 \%)$ \\
Total & 40 & $15 / 40(37,5 \%)$ \\
\hline
\end{tabular}

A tabela 5 mostra a correlação entre a ocorrência de edema ou coleção e o tempo de duração da cirurgia. Nos 14 pacientes em que esse tempo foi menor que 4 horas, ocorreram 4 casos de coleção correspondendo a percentual de $28,5 \%$, ao passo que, nos 26 que permaneceram por 4 horas ou mais em cirurgia, ocorreram 11 casos de coleção, ou seja, 42,3\%.

$\mathrm{Na}$ tabela 6, foram separados os dois grupos do presente trabalho, apresentando o número de casos em que houve acúmulo líquido subgaleal em cada um deles. No grupo em que foi realizado curativo com capacete, houve apenas 1 caso com coleção e, no grupo em que se realizou curativo simples, 14 casos.

\begin{tabular}{ccc}
\hline \multicolumn{4}{c}{ Tabela 5} \\
Incidência de coleção em função da duração da operação \\
\hline Duração (horas) & Número de pacientes & Incidência de coleção \\
\hline 1 & 1 & $0 / 1(0,0 \%)$ \\
2 & 2 & $0 / 1(0,0 \%)$ \\
3 & 11 & $4 / 11(36,3 \%)$ \\
4 & 15 & $7 / 15(46,6 \%)$ \\
5 & 3 & $2 / 3(75,0 \%)$ \\
6 & 4 & $0 / 4(0,0 \%)$ \\
7 & 3 & $1 / 3(66,6 \%)$ \\
13 & 1 & $1 / 1(100 \%)$ \\
Total & 40 & $15 / 40(37,5 \%)$ \\
\hline
\end{tabular}

\begin{tabular}{cc}
\multicolumn{2}{c}{ Tabela 6} \\
Incidência de coleção nos dois grupos estudados \\
\hline Tipo de curativo & Presença de acúmulo líquido \\
\hline Capacete & $1 / 20(5,0 \%)$ \\
Simples & $14 / 20(70,0 \%)$ \\
Total & $15 / 40(37,5 \%)$ \\
\hline
\end{tabular}

\section{Discussão}

Pudemos observar que, quanto mais se alonga o tempo cirúrgico, maior é a chance de se ter acúmulo de líquido no tecido subgaleal durante o período pósoperatório, conforme o que se observa da comparação entre os procedimentos com menos de 4 horas e os mais demorados. O retalho cutâneo dobrado e preso para manter exposta a região da craniotomia dificulta o retorno venoso, proporcionando acúmulo de líquido tecidual, e quanto maior o tempo cirúrgico mais o retalho fica dobrado.

Verificou-se incidência maior de coleção nas incisões feitas no sentido sagital, como na pterional, que naquelas feitas no sentido coronal, como na bicoronal, o que pode ser explicado pela orientação do fluxo de irrigação e drenagem do couro cabeludo. Ao se fazer incisão no sentido sagital, o número de vasos de 
irrigação e drenagem (pequenos e microvasos) lesado pelos instrumentos cirúrgicos é maior que no sentido coronal, muito embora a incisão bicoronal seja maior, em extensão, que a maioria das incisões longitudinais.

Embora não fosse o objetivo do trabalho analisar detalhadamente cada fator que pudesse produzir coleção ou edema, pudemos observar que não houve diferença significativa ao se levar em conta dados como sexo, idade, cor e presença de hipertensão arterial, o mesmo ocorrendo com pacientes operados em caráter de urgência ou eletiva.

O capacete mostrou-se eficaz, evitando acúmulo de líquido em 19 dos 20 pacientes em que esse foi realizado, falhando apenas em um caso, cuja cirurgia demorou 7 horas; tratava-se de um paciente portador de tumor de hipófise com acromegalia e hipertrofia de todos os tecidos.

Já entre os pacientes que não usaram capacete, houve uma incidência bem maior de acúmulo de líquido observado em 14 entre 20 (70\%), comprovando que o curativo realizado com a técnica descrita neste trabalho é fator decisivo na prevenção do edema ou coleção subgaleal.

Os curativos com capacete realizados neste trabalho buscaram proporcionar conforto aos pacientes, pois não são demasiadamente apertados e protegem adequadamente as orelhas. Recorde-se que o pavilhão auricular quando comprimido intensamente pelo enfaixamento é sede de dor e incômodo para o paciente, que geralmente solicita a retirada do curativo.

Não precisamos retirar nenhum dos curativos com capacete antes das 48 horas previstas, o que indica que houve proteção auricular sob tensão adequada da faixa-crepe, com conforto para o paciente. Outra vantagem desse método é o fato de as faixas serem dispostas em dois sentidos (ao redor do crânio e abrangendo mandíbula, occipital, parietal e temporal), o que prende muito bem o curativo dificultando sua retirada por aqueles pacientes agitados, que normalmente perdem o capacete quando este é enrolado somente ao redor do crânio. A região temporal é a zona que mais freqüentemente acumula líqüido subgaleal, e o enfaixamento nos dois sentidos que se cruza justamente nessa região colabora bastante para evitar o edema e a coleção temporal.

\section{Conclusões}

O capacete mostrou-se muito eficaz na prevenção do edema e da coleção subgaleais pós-operatórios.

Cirurgias com duração superior a 4 horas têm maior probabilidade de provocar acúmulo de líquido tecidual subgaleal no período pós-operatório. Assim também são as incisões feitas no sentido sagital em relação àquelas feitas no sentido coronal.

O curativo deve buscar não só a prevenção do acúmulo de líquido subgaleal como também a facilidade de higiene e o conforto dos pacientes.

Original recebido em fevereiro de 2002

Aceito para publicação em setembro de 2002

\section{Endereço para correspondência:}

Antonio Carlos Montanaro

Rua Maestro Cardim, 769, bloco I, sala 235

CEP 01323-001 - São Paulo, SP 